\title{
Inadequate prescription of chronic consumption of proton pump inhibitors in a hospital in Mexico. Cross-sectional study
}

\author{
Jaime Alberto Sánchez-Cuén ${ }^{1}$, Ana Bertha Irineo-Cabrales ${ }^{1}$, Gregorio Bernal-Magaña ${ }^{1}$ \\ and Felipe de Jesús Peraza-Garay²
}

${ }^{1}$ Department of Gastroenterology. Hospital Regional del Instituto de Seguridad y Servicios Sociales de los Trabajadores del Estado. Culiacán, Sinaloa. México. ${ }^{2}$ Universidad Autónoma de Sinaloa. Centro de Investigación y Docencia en Ciencias de la Salud. Culiacán, Sinaloa. México

\begin{abstract}
Introduction: PPIs have been an enormous therapeutic advance in acid-related diseases. However, it has been detected an abuse in its consumption. The aim of this study was to determine the frequency of inadequate prescription of chronic use of PPIs in outpatients in a speciality hospital.

Material and methods: we performed a cross-sectional descriptive study review. The study population were patients, chronic users of proton pump inhibitors (PPIs), attending outpatient consult in a hospital of government workers. We defined as chronic user of PPIs that patient that takes medication daily for over a year and inappropriate prescription, that one that has not been approved by the clinical guidelines. A simple random sampling was utilized. The following parameters were investigated: diagnosis and prescription of PPIs, time of use, at which level of care PPIs were prescribed (primary care or specialist), self-medication, with or without endoscopy. For the statistical analysis, we used Student's t-test and Chi-square, $95 \%$ confidence intervals and significance $0.05 \%$.

Results: we reviewed 153 patients, 40 (26.1\%) men and 113 $(73.9 \%)$ women, mean age $58 \pm 11.4$ years. The prescription of chronic treatment with PPIs was adequate in $64.7 \%$ of patients and inadequate in $35.3 \%$. The most common appropriate prescription $(31.3 \%)$ of chronic use of PPIs was due to gastroesophageal reflux disease. The most common inadequate prescription was absence of diagnosis (22.2\%), polypharmacy without nonsteroidal antiinflammatory drugs (16.6 \%) and chronic gastritis (16.6\%). History of endoscopy were not statistically significant.

Conclusions: the frequency of inappropriate prescriptions of chronic use of PPIs was high, around $35.3 \%$, similar to those reported in hospitals in developed countries.
\end{abstract}

Key words: Proton Pump Inhibitors. Chronic consumption.

Received: 02-09-2012

Accepted: 20-11-2012

Correspondence: Jaime Alberto Sánchez-Cuén. Department of Gastroenterology. Hospital Regional ISSSTE de Culiacán. Calzada. Heroico Colegio Militar 875 Sur, colonia 5 de Mayo. 80000 Culiacán, Sinaloa. México e-mail: sanchezcuen_jaime@ hotmail.com
Sánchez-Cuén JA, Irineo-Cabrales AB, Bernal-Magaña G, Peraza-Garay FJ. Inadequate prescription of chronic consumption of proton pump inhibitors in a hospital in Mexico. Cross-sectional study. Rev Esp Enferm Dig 2013;105:131-137.

\section{INTRODUCTION}

The proton pump inhibitors (PPIs) are some of the most common types of prescribed drugs in the world because they combine high efficacy with low toxicity. PPIs occupy $80 \%$ of all prescriptions for these drugs in the United Kingdom, its prescription has doubled without obvious reasons. Although it is assumed that the prescription occurs mainly in primary care health, there is evidence of its high abuse in secondary care. PPIs have been an enormous therapeutic advance, especially improving the quality of life in the long term of patients with symptoms of GERD and its complications, as well as acid-related gastroduodenal diseases in the short term treatments. However, these are clearly excellent drugs used in excess in long term treatment (1). Since their introduction in the late 80s, PPIs (omeprazole, esomeprazole, lansoprazole, pantoprazole and rabeprazole) have substantially improved the treatment of acid-related diseases. PPIs are the most potent inhibitors of the production of acid and are most effective when the parietal cell is stimulated to produce postprandial acid. The differences in clinical efficacy between the various PPIs are small, as are clear differences when compared to their costs (2).

There are clinical practice guidelines such as the Australian Government Department of Health in 2011 with recommendations for the proper use of PPIs. The widely recognized prescriptions for PPIs therapy are: gastroesophageal reflux disease (GERD) with and without esophagitis, in endoscopic confirmation of peptic ulcer disease, nonulcer dyspepsia, Barrett's esophagus, Zollinger Ellison syndrome, peptic esophageal stricture scleroderma, short treatment of ulcer disease as part of the treatment regimen 
for eradication of Helicobacter pylori $(\mathrm{Hp})$ and consumption prophylaxis of nonsteroidal antiinflammatory drugs (NSAIDs). The latter, especially when you can deduct a higher risk of dyspepsia or ulceration, that is, when they meet two or more of the following criteria: patients with more than 65 years, history of peptic ulcer disease, previous serious gastrointestinal complications, especially gastrointestinal bleeding, concomitant use of steroids or oral anticoagulants, prolonged use of high doses of NSAIDs, comorbidity with cardiovascular, renal or hepatic diabetes and hypertension. Regarding the length of PPIs therapy, it should be considered for satisfactory response an initial course of 4-8 weeks with the standard dose. Between 20-40\% of patients with GERD will not require another prescription in 6-12 months. It should be considered, although it is not absolutely proven, the strategy of gradually reducing the dose of PPIs. In summary, it can be stated that the well-established guidelines for chronic treatment with PPIs are: severe esophagitis (Los Angeles classification grade C and D), Barrett's esophagus, Zollinger Ellison syndrome, scleroderma and peptic esophageal stricture in the treatment and prophylaxis with NSAIDs (3). Other clinical guidelines add other prescriptions for use of PPIs as peptic ulcer bleeding, prophylaxis in stress ulcer in high risk patients (4-6) and their use in chronic disease with endoscopic GERD normal with or without pathological pHmetry (7). PPIs treatment with intermittent demand, while not as effective as continuous treatment, they are still alternatives to be considered in the treatment of patients with chronic $\operatorname{GERD}(8,9)$.

Safety and tolerability of PPIs are factors to be considered in elderly patients requiring chronic use of PPIs, which usually have concomitant chronic diseases (10). Overall PPIs are a very safe drug with minor and infrequent side effects. The most commonly described include headache, constipation, diarrhea, rashes, no described cases of cancer associated with prolonged use of these drugs (11). PPIs can promote the development of gastritis predominantly in the gastric body in Hp positive patients, thus accelerating the development of atrophic gastritis (12). However, no evidence of increase in the proportion of intestinal metaplasia or dysplasia associated with chronic use of PPIs with or without Hp infection. It is well known that hypergastrinemia generated by long-term use of PPIs stimulates hyperplasia of gastric enterochromaffin cells, but nevertheless cases of carcinoid tumor progression have not been detected (13). Other more controversial side effects have been mentioned, such as: rebound acid hypersecretion syndrome $(14,15)$, fragility fractures (16), interstitial nephritis (17), pneumonia $(18,19)$, vitamin B12 deficiency $(20,21)$, gastric polyposis $(22,23)$. Also, long-term therapy with PPIs can cause electrolyte abnormalities such as symptomatic hypocalcemia and severe hypomagnesemia $(24,25)$. High doses of PPIs may determine the onset of intestinal bacterial overgrowth $(26,27)$. Some studies have documented a modest increase in the risk of bone fractures, a risk that increases in relation to the dose and duration of treatment with PPIs (28). The loss of the normal stomach acidity has been associated with the colonization of the upper gastrointestinal tract. Hence, it is plausible that the increase in stomach $\mathrm{pH}$ with acid suppressive therapy may lead to an increased load of pathogenic microbes such as Clostridium difficile, salmonella, campylobacter and shigella $(29,30)$.PPIs drug interactions occur through several mechanisms, the most important include the competitive inhibition of cytochrome P-450 involved in drug metabolism, and the alteration of the absorption of other drugs by changes in gastric $\mathrm{pH}$ levels $(31,32)$. Studies have been conducted and published to determine the percentage of inappropriate prescriptions of PPIs. Some results in the United Kingdom, Walker and McDonald (33) in 2001, in Spain, Burgos et al. (34) and Martin-Echevarría et al. (35) in 2003, indicate that these percentages are $67 \%, 65.4 \%$ and $68.1 \%$, respectively. In Swansea, United Kingdom, Batuwitage et al. (36), in 2006, found that $54 \%$ of patients were prescribed PPIs inappropriately. In Ireland, Cahir et al., in 2007, found that in only $36 \%$ of patients, chronic treatment with PPIs were correctly indicated (37). In Germany, Ahrens et al. (38), in 2010, showed that $54.5 \%$ of PPIs prescriptions did not meet the recommendations for the prescription of chronic treatment with PPIs.

Our working hypothesis was to determine the frequency of inadequate prescription of chronic use of PPIs in a hospital outpatient specialty, considering that in the literature the frequency of this inappropriate prescription is over $60 \%$.

\section{MATERIAL AND METHODS}

We performed an observational, descriptive, prospective, survey type cross-sectional design. The study was approved by the Research and Ethics Committee of the Regional Hospital of the Institute of Security and Social Services for State Workers in Culiacán Sinaloa as it does not violate the concepts of authorship, plagiarism, conflict of interest and informed consent.

The study population was sampled from outpatients in a government hospital for state workers in a province in northwestern Mexico, all chronic users of PPIs, attending outpatient care, during the period from February to May 2012.

Inclusion criteria were: patients of both genders, aged 25 to 80 years old, daily consumption of PPIs for a year or more. Informed consent was obtained. Exclusion criteria were lack of confidence in the answers to the questions provided, and disabled patients. Disposal criteria include errors or loss of data collection of the study variables.

Variable definition. We defined chronic user of PPIs as a person who took the medication daily for one or more years. Appropriate prescription of chronic use of PPIs and supported by clinical guidelines as the Australian Government Department of Health (3), Clinical guidelines for the diagnosis and treatment of gastroesophageal reflux disease and Clinical Practice Guideline Update 2007 by the Spanish 
Association of Gastroenterology, Spanish Society of Family and Community Medicine and Cochrane Collaboration, were: GERD, mild and severe esophagitis (Los Angeles classification Grade A, B and C, D, respectively), Barrett's esophagus, Zollinger Ellison syndrome, scleroderma and esophageal stenosis and prophylaxis in NSAID consumption when two or more of the following criteria are met: $\geq 65$ years, history of peptic ulcer disease, previous serious gastrointestinal complications, concomitant use of steroids or oral anticoagulants, prolonged use of high doses of NSAIDs, comorbidity with cardiovascular disease, kidney or liver disease, diabetes and hypertension, and endoscopy negative GERD pHmetry normal or pathological (Table I). Inadequate prescription for chronic use of PPIs that do not meet the clinical guidelines mentioned above.

The sampling method was random systematic probabilistic sampling. The procedure is described as follows: the consult area was requested the daily outpatient programming list, morning and evening programming, of those patients with appointments in the hospital. All specialties are included with exception of pediatrics patients; patients were enumerated by performing a sampling frame. Numeric data were captured in an Excel file. It was determined that twenty daily interviews were to be performed, and using a randomized number, patients were chosen, the turn, the consult room, and the specialty were identified.

Patients who met the selection criteria underwent an interview, filling out the form with the patient's identification and capture of variables such as age, gender, and file number. Closed, structured questions were conducted to obtain a response to variables such as type of PPIs medication used, prescription level or primary care specialty, history of endoscopy. The information was then verified with healthcare records in clinical records, and findings of endoscopy were reported, if any. If the answers matched, the patient was included in the study, if the information did not match, or false information was provided, the patient was not included.

The sample size for the proportion to detect a difference between the hypothetical and alternative hypotheses 0.10 (Delta) was 153 patients. The proportion of null hypothesis is assumed to be 0.50 and 0.60 under the alternative. The test statistic used was the one-sided test (one-tailed) of $\mathrm{Z}$. The significance level of the test was 0.05 and power of 0.80 .

\section{Table I. Appropriate prescription for chronic use of PPIs}

Gastroesophageal reflux disease

Barrett's esophagus

Zollinger Ellison Syndrome

Scleroderma peptic esophageal stenosis

Prophylaxis of NSAID consumption ( $\geq 2$ criteria)

Erosive esophagitis (Los Angeles classification A, B, C, D)

GERD endoscopic normal with or withput pathological pHmetry

${ }^{*}$ Clinical Guidelines $(3,7-9)$
Statistical Analysis. We used SPSS v 16 (SPSS, inc., Chicago IL, USA). In the analysis of descriptive statistics for quantitative variables with measures of central tendency and dispersion; categorical variables were presented as percentages. For inferential statistics for quantitative variables, point estimates were presented as well as confidence intervals. We used the Student's t-test, and Chi-square test for categorical variables. Graphs and tables are presented for both variables. We considered a statistical significance of 0.05 with a $95 \%$ confidence.

\section{RESULTS}

We studied a group of 153 patients, 40 male $(26.1 \%)$ and 113 female $(73.9 \%)$, the mean age was $58 \pm 11.4$ years. The prescription of PPIs was conducted in $26.8 \%$ in primary care health, $65.4 \%$ in specialties and as self-medication in $7.8 \%$. PPIs used chronically by the patient were omeprazole and esomeprazole in $78.4 \%, 21.6 \%$, respectively.

In 99 patients $(64.7 \%)$ the prescription in chronic use of PPIs was correct, while 54 patients $(35.3 \%)$ was inadequate (Fig. 1).

The percentages in appropriate prescriptions in chronic use of PPIs were: 31 GERD patients (31.3\%), $27(27.3 \%)$ because of erosive esophagitis with grade A or B of the Los Angeles classification, $25(25.3 \%)$ as prophylaxis before continued consumption of NSAID, 14 (14.1\%) with erosive esophagitis with the grade C or D of the Los Angeles classification, 1 patient ( $1 \%$ ) with Barrett's esophagus and 1 patient (1\%) with GERD and normal endoscopy and pathological pHmetry (Fig. 2).

Inadequate prescriptions for chronic use of PPIs were: $12(22.2 \%)$ prescription without diagnosis, 9 (16.7 \%) without NSAIDs polypharmacy, $9(16.7 \%)$ with chronic gastritis, $8(14.8 \%)$ with mild surface gastritis, 7 (13\%) taking sporadic or low-dose of NSAIDs, $4(7.4 \%)$ with non-ulcer dyspepsia, 2 (3.7\%) with intestinal metaplasia, $2(3.7 \%)$

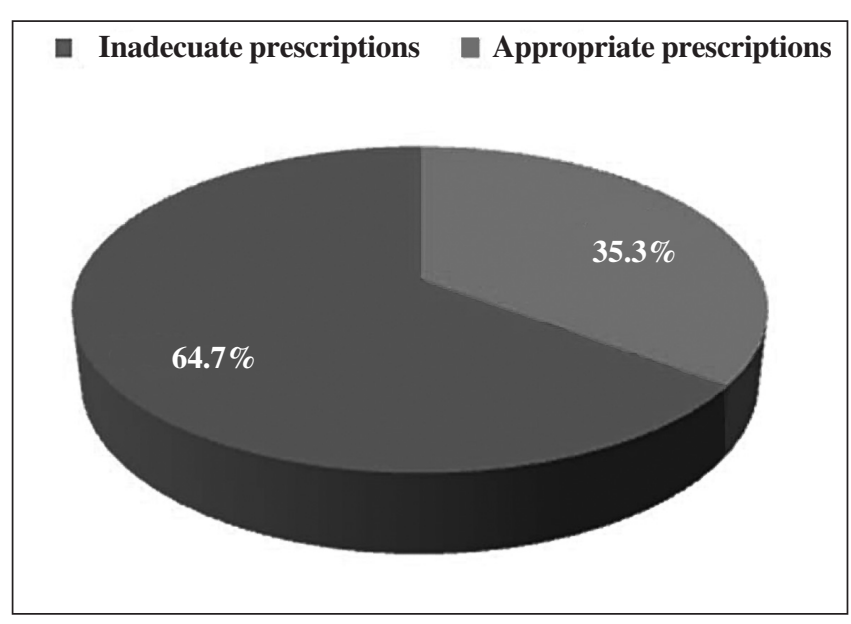

Fig. 1. Inadequate prescriptions/appropriate prescriptions. 


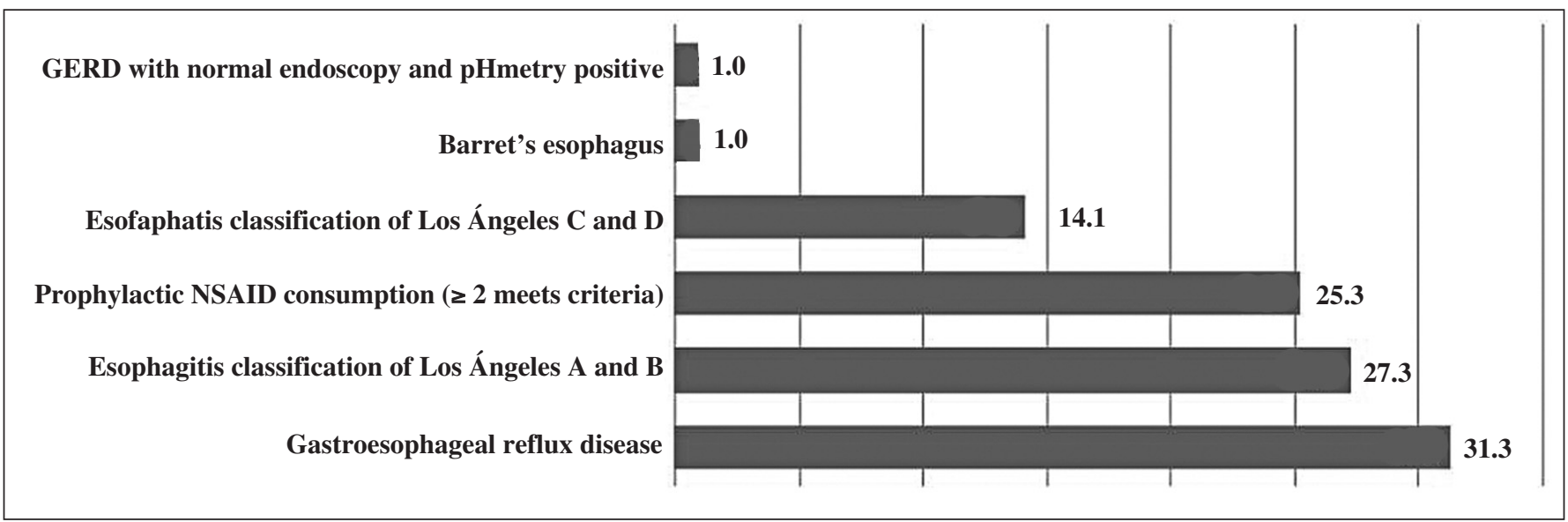

Fig. 2. Appropriate prescriptions for chronic use PPIs (\%).

with upper gastrointestinal bleeding, and $1(1.9 \%)$ after endoscopic confirmation of ulcer disease (Fig. 3).

In 76 patients ( $49.7 \%$ ), a diagnostic endoscopy had been practiced and 77 patients $(50.3 \%)$ were treated with PPIs without previous endoscopy. No differences did exist regarding gender. Correct indication was in 10 men (25\%) and 31 women $(27.4 \%)$ and incorrect, in 30 men (75\%) and 82 women $(72.6 \%)(p=0.470)$. The mean age of patients with appropriate and inappropriate indications were $58 \pm 10.3$ and $58.1 \pm 13.2$ years $(p=0.963)$, respectively. Primary care physicians reported prescribing PPIs adequately in $30(73.2 \%) v s .69$ patients $(69 \%)$ in specialized care. The prescription was therefore inadequate in 11 patients $(26.8 \%)$ in primary care compared with 31 patients $(31 \%)$ at hospitals $(\mathrm{p}=0.391)$. Fifty four $(71.1 \%)$ and 45 $(58.4 \%)$ of patients with and without a history of endoscopy had appropriate prescription of PPIs respectively. Also, 22 $(28.9 \%)$ and $32(41.6 \%)$ of patients with and without a history of endoscopy had inadequate prescription of PPIs respectively $(\mathrm{p}=0.072)$ (Table II).

\section{DISCUSSION}

PPIs have substantially improved the treatment of acidrelated diseases and have an excellent safety profile; PPIs are one of the most commonly prescribed drugs in both primary and specialized attention. However, chronic use has shown some rare side effects such as vitamin B12 deficiency, brittle bones and fractures, hypomagnesemia, hypokalemia, gastric fundic polyposis, infectious enteritis, drug interactions, rebound syndrome of gastric hypersecretion, as well as susceptibility to pneumonia. Although rare, these effects must be taken into account particularly in inadequate prescriptions, which occur worldwide and range between 20 and $75 \%$. Our study found $35.3 \%$ of inappropriate prescriptions of chronic use of PPI, being more frequent in females $(73.9 \%)$. The PPI that is prescribed more frequently is omeprazole $(78.4 \%)$. The most common adequate prescription was GERD (31.3\%), followed by erosive esophagitis with Los Angeles classification A and B (27.3\%) and prophylaxis of NSAID consumption (25.3\%). The most frequent inadequate

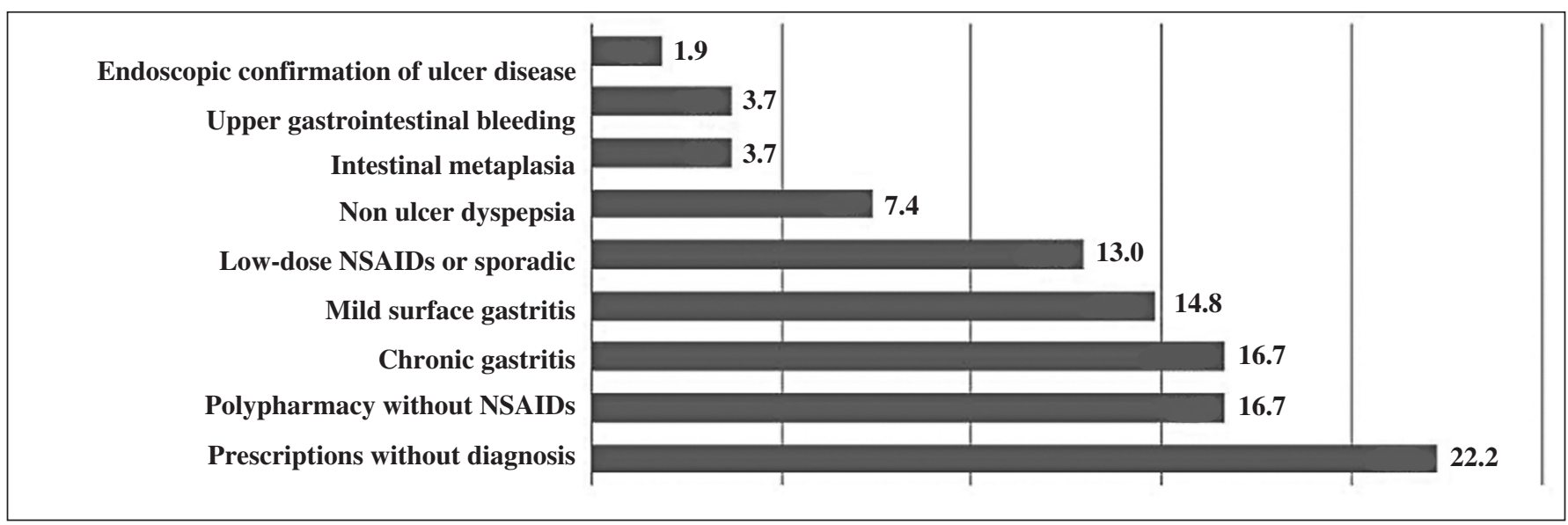

Fig. 3. Inadequate prescriptions for chronic use PPIs (\%). 
Table II. Association of research variables with prescriptions in the chronic use of PPIs

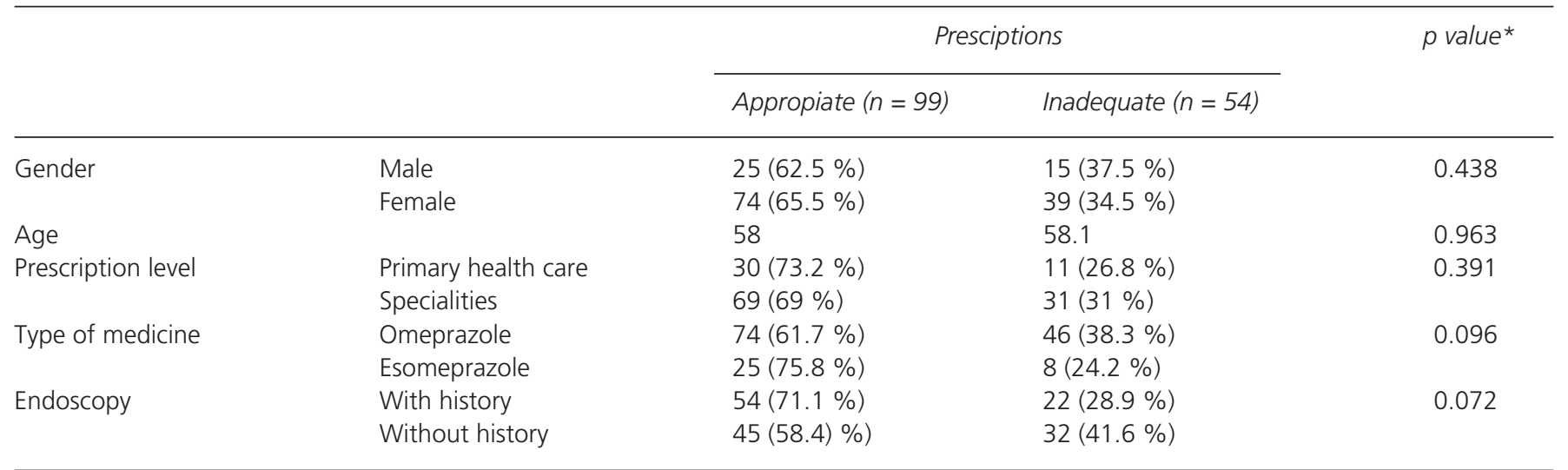

${ }^{*} p \leq 0,05$

prescriptions were no diagnosis $(22.2 \%)$, polypharmacy without NSAIDs (16.7\%), and chronic gastritis (16.7 \%). Research in developed countries on PPIs prescribing patterns, such as the one conducted by Walker and McDonald (33), demonstrated an inadequate prescription of $67 \%$ of patients. Batuwitage et al. (36), in the United Kingdom, found an incorrect prescription of PPIs in $56 \%$ of patients; likewise de Burgos-Lunar et al. (34) found that the prescription of PPIs was adjusted in only $36.4 \%$ of the appropriate criteria. In Spain, Martin-Echevarria et al. (35) observed inappropriate prescriptions of PPIs in $68.1 \%$ of cases; while in Germany, Ahrens et al. (38) demonstrated that $54.5 \%$ of prescriptions did not meet the recommendations for the prescription of PPIs. Also, in Ireland, Cahir et al. (37), in 2007 found that chronic treatment with PPI was correctly prescribed in only $36 \%$ of patients. We conclude that our study is consistent with the reported results (Table III).

Chronic use of PPIs without an appropriate prescription may show a lack of knowledge regarding their prescription protocols and a probable lack of coordination between the different levels of care, which could be corrected with the development of protocols for good practice in the care of

Table III. Results from different studies in chronic use of PPIs

\begin{tabular}{llll}
\hline & \multicolumn{3}{c}{ Prescriptions } \\
\cline { 2 - 4 } & Inadequate & Appropriate & $\begin{array}{l}\text { Uncertain } \\
\text { indication }\end{array}$ \\
& & & $3 \%$ \\
\hline Walker y McDonald (33) & $67 \%$ & $30 \%$ & $36 \%$ \\
De Burgos Lunar et al. (34) & $65.40 \%$ & $36.40 \%$ & \\
Martín-Echeverría et al. (35) & $68.10 \%$ & $31.90 \%$ & \\
Batuwitage et al. (36) & $54 \%$ & $46 \%$ & $12.70 \%$ \\
Cahir et al. (37) & $36 \%$ & $64 \%$ & $32,70 \%$ \\
Ahrens et al. (38) & $54.50 \%$ & $64.70 \%$ & \\
This study & $35.30 \%$ & & \\
& & &
\end{tabular}

patients requiring PPI. This occurs not only in hospitals in developing countries but also in developed countries, as they are not strangers to this high frequency of inappropriate prescriptions. The guidelines in clinical practice may improve adherence to appropriate prescribing of PPIs, claiming that the benefits would be obtained with health policy actions, raising awareness for their rational use and avoiding adverse effects reported in scientific publications to strengthen Hospital Insurance programs. We conclude that the frequency of inadequate instructions on the prescription of chronic PPIs is still high and $35.3 \%$ similar to other hospitals in developed countries.

\section{REFERENCES}

1. Forgacs I, Loganayagan A. Overprescribing proton pump inhibitors. BMJ 2008;336:2-3.

2. Cienfuegos Alfredo. Series: from physiology to the clinic: Gastric secretion and proton pump inhibitors. Rev Col Gastroenterol 2010;25:94-8.

3. National Prescribing Service. Proton pump inhibitors. Citado en http://www.nps.org.au/_data/assets/pdf_file/0012/111423/clinical_guid ance_final_PPI.pdf

4. Nardino RJ, Vender RJ, Herbert PN. Overuse of acid-suppressive therapy in hospitalized patients. Am J Gastroenterol 2000;95:3118-22.

5. Noguerado Asensio A, Rodríguez Barrientos R, Zelaya Castro P, Sánchez Sempere A, Antuña Blanco F, Lutz García E, et al. Use of acid-suppressive medications in hospitalized patients. An Med Interna 2002; 19:557-60.

6. Ponce Romero M, Berenguer Lapuerta J. Indicaciones actuales de los inhibidores de la bomba de protones. Rev Clin Esp 2003;203:136-8.

7. Garrigues V, Bastida G, I. Bau I, Ponce J. Gastroesophageal reflux with normal endoscopy. What can be done? Rev Sdad Valenciana Patol Dig 2000;19:141-51.

8. DeVault KR, Castell DO; American College of Gastroenterology. Updated guidelines for the diagnosis and treatment of gastroesophageal reflux disease. Am J Gastroenterol 2005; 100:190-200.

9. Elsevier Doyma, S.L. Grupo de trabajo de la guía de práctica clínica sobre ERGE. Manejo del paciente con enfermedad por reflujo gastroesofágico (ERGE). Guía de Práctica Clínica. Actualización 2007. Asociación Española de Gastroenterología, Sociedad Española de Medicina de Familia y Comunitaria y Centro Cochrane Iberoamericano; 2007. Programa de Elaboración de Guías de Práctica Clínica en Enfermedades Digestivas, desde la Atención Primaria a la Especializada: 1. Barcelona, marzo 2007.

10. Sobrino-Cossío S, López-Alvarenga JC, Remes-Troche JM, GalvisGarcía ES, Soto-Pérez JC, Teramoto-Matsubara O, et al. Proton pump 
inhibitors in gastroesophageal reflux disease: "a custom-tailored therapeutic regimen”. Rev Esp Enferm Dig 2012;104:367-78.

11. Martín de Argila de Prados C. Security of proton pump inhibitors. Rev Esp Enferm Dig 2011;103:98.

12. Martínez M JD, Henao R SC. Consumo crónico de medicamentos inhibidores de la bomba de protones (IBP) y el desarrollo de gastritis atrófica corporal. Rev Col Gastroenterol 2007;22(Pt 4):302-307.

13. Doweck J. Adverse effects of proton pump inhibitors. Acta Gastroenterol Latinoam 2009:39:219-22.

14. Reimer C, Søndergaard B, Hilsted L, Bytzer P. Proton-pump inhibitor therapy induces acid-related symptoms in healthy volunteers after withdrawal of therapy. Gastroenterology 2009;137:80-7.

15. Niklasson A, Lindström L, Simrén M, Lindberg G, Björnsson E. Dyspeptic symptom development after discontinuation of a proton pump inhibitor: a double-blind placebo-controlled trial. Am J Gastroenterol 2010;105:1531-7.

16. Insogna KL. The effect of proton pump-inhibiting drugs on mineral metabolism. Am J Gastroenterol 2009;104(Supl.2):S2-4.

17. Simpson IJ, Marshall MR, Pilmore H, Manley P, Williams L, Thein $\mathrm{H}$, et al. Proton pump inhibitors and acute interstitial nephritis: report and analysis of 15 cases. Nephrology (Carlton) 2006;11:381-5.

18. Gulmez SE, Holm A, Frederiksen H, Jensen TG, Pedersen C, Hallas J. Use of proton pump inhibitors and the risk of community-acquired pneumonia: a population-based case-control study. Arch Intern Med 2007;14;167:950-5

19. de Jager CP, Wever PC, Gemen EF, van Oijen MG, van GageldonkLafeber AB, Siersema PD et al. Proton pump inhibitor therapy predisposes to community-acquired Streptococcus pneumoniae pneumonia. Aliment Pharmacol Ther 2012;36:941-9.

20. Sagar M, Janczewska I, Ljungdahl A, Bertilsson L, Seensalu R. Effect of CYP2C19 polymorphism on serum levels of vitamin B12 in patients on long-term omeprazole treatment. Aliment Pharmacol Ther 1999; b13:453-8.

21. Hirschowitz BI, Worthington J, Mohnen J. Vitamin B12 deficiency in hypersecretors during long-term acid suppression with proton pump inhibitors. Aliment Pharmacol Ther 2008;27:1110-21.

22. Oh S. Proton pump inhibitors uncommon adverse effects. Aust Fam Physician 2011;40:705-8.

23. Jalving M, Koornstra JJ, Wesseling J, Boezen HM, DE Jong S, Kleibeuker JH. Increased risk of fundic gland polyps during long-term proton pump inhibitor therapy. Aliment Pharmacol Ther 2006;24:1341-8.

24. Mackay JD, Bladon PT. Hypomagnesaemia due to proton-pump inhibitor therapy: a clinical case series. QJM 2010;103:387-95.
25. Hoorn EJ, van der Hoek J, de Man RA, Kuipers EJ, Bolwerk C, Zietse R. A case series of proton pump inhibitor-induced hypomagnesemia. Am J Kidney Dis 2010;56:112-6.

26. Raña Garibay R. Efectos adversos y falla a los inhibidores de la bomba de protones (IBP). Rev Gastroenterol Méx 2011;76(supl.1): 49-52.

27. Lombardo L, Foti M, Ruggia O, Chiecchio A. Increased incidence of small intestinal bacterial overgrowth during proton pump inhibitor therapy. Clin Gastroenterol Hepatol 2010;8:504-8.

28. Laine L. Proton pump inhibitors and bone fractures? Am J Gastroenterol 2009;104 (Supl. 2): 21-6.

29. Leonard J, Marshall JK, Moayyedi P. Systematic review of the risk of enteric infection in patients taking acid suppression. Am J Gastroenterol 2007;102:2047-56.

30. Linney S, Fernandes T, Einarson T, Sengar A, Walker JH, Mills A. Association Between Use of Proton Pump Inhibitors and a Clostridium difficile-Associated Disease Outbreak: Case-Control Study. Can J Hosp Pharm 2010;63:31-7.

31. Gerson LB, Triadafilopoulos G. Proton pump inhibitors and their drug interactions: an evidence-based approach. Eur J Gastroenterol Hepatol 2001;13:611-6.

32. Labenz J, Petersen KU, Rösch W, Koelz HR. A summary of Food and Drug Administration-reported adverse events and drug interactions occurring during therapy with omeprazole, lansoprazole and pantoprazole. Aliment Pharmacol Ther 2003;17:1015-9.

33. Walker NM, McDonald J. An evaluation of the use of proton pump inhibitors. Pharm World Sci 2001;23:116-7.

34. de Burgos Lunar C, Novo del Castillo S, Llorente Díaz E, Salinero For M A. Study of prescription-indication of proton pump inhibitors. Rev Clin Esp 2006;206:266-70.

35. Martín-Echevarría E, Pereira Juliá A, Torralba M, Arriola Pereda G, Martín Dávila P, Mateos J, et al. Assessing the use of proton pump inhibitors in an internal medicine department. Rev Esp Enferm Dig 2008;100:76-81.

36. Batuwitage BT, Kingham JG, Morgan NE, Bartlett RL. Inappropriate prescribing of proton pump inhibitors in primary care. Postgrad Med J 2007:83:66-8.

37. Cahir C, Fahey T, Teeling M, Teljeur C, Feely J, Bennett K. Potentially inappropriate prescribing and cost outcomes for older people: a national population study. Br J Clin Pharmacol 2010;69:543-52.

38. Ahrens D, Chenot JF, Behrens G, Grimmsmann T, Kochen NM. Appropriateness of treatment recommendations for PPI in hospital discharge letters. Eur J Clin Pharmacol 2010 66:1265-127. 